Title:

Design of a Neutrino Oscillation Experiment

Author(s):

Fred Federspiel, P-25

Submitted to:

DOE Office of Scientific and Technical Information (OSTI)

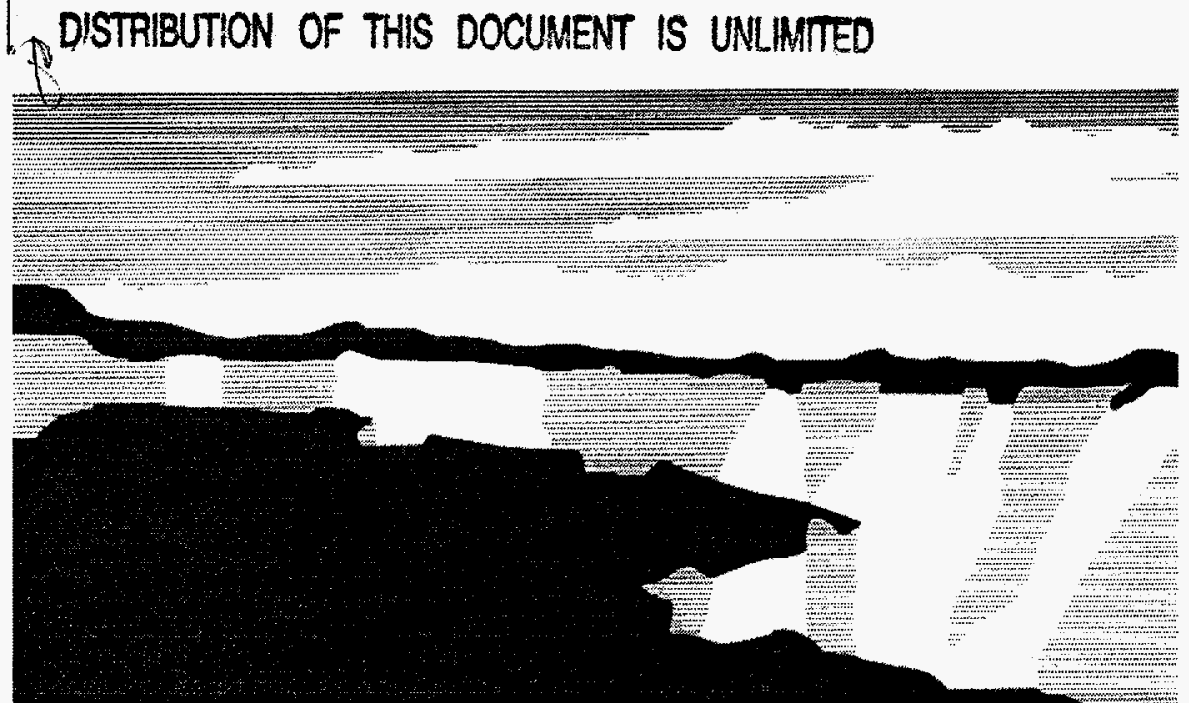

Los Alamos National Laboratory, an affirmative action/equal opportunity employer, is operated by the University of California for the U.S. Department of Energy under contract W-7405-ENG-36. By acceptance of this article, the publisher recognizes that the U.S. Government retains a nonexclusive, royaltyfree license to publish or reproduce the published form of this contribution, or to allow others to do so, for U.S. Government purposes. The Los Alamos National Laboratory requests that the publisher identify this article as work performed under the auspices of the U.S. Department of Energy. 


\section{DISCLAIMER}

Portions of this document may be illegible in electronic image products. Images are produced from the best available original document. 


\section{DISCLAIMER}

This report was prepared as an account of work sponsored by an agency of the United States Government. Neither the United States Government nor any agency thereof, nor any of their employees, makes any warranty, express or implied, or assumes any legal liability or responsibility for the accuracy, completeness, or usefulness of any information, apparatus, product, or process disclosed, or represents that its use would not infringe privately owned rights. Reference herein to any specific commercial product, process, or service by trade name, trademark, manufac. turer, or otherwise does not necessarily constitute or imply its endorsement, recommendation, or favoring by the United States Government or any agency thereof. The views and opinions of authors expressed herein do not necessarily state or reflect those of the United States Government or any agency thereof. 


\title{
Design of a Neutrino Oscillation Experiment
}

\author{
Fred Federspiel*
}

\begin{abstract}
This is the final report of a one-year, Laboratory-Directed Research and Development (LDRD) project at the Los Alamos National Laboratory (LANL). The project sought to make a preliminary conceptual design and technical evaluation for a neutrino detector with high mass and particle identification capability. The detector will use recent improvements in imaging technology. In addition, a special Monte Carlo code was designed to address contamination of the muon neutrino beam by other particles. The combination of these two developments could lead to significant improvements in both neutrino production sources and neutrino detectors.
\end{abstract}

\section{Background and Research Objectives}

The purpose of this project was to lay the foundation for a major new experimental initiative in the rapidly changing field of neutrino physics. We are developing the technologies needed to mount a definitive measurement of neutrino oscillations. We plan to carry out this measurement using the Fermi National Laboratory booster, which will give us several advantages over our current liquid scintillator neutrino detector (LSND) experiment at the Los Alamos Neutron Scattering Center (LANSCE).

To a large extent, the detectors for the new experiment will copy the successful design of LSND, but an important additional functionality needs to be developed. For the near detector especially, more information needs to be extracted concerning track length than is available with the LSND design. One promising method for obtaining this additional information makes use of recent developments in intensified charged-coupled device (CCD) arrays along with large light-gathering lenses to image the scintillation light produced along the track. So far, such devices have not been applied to the design of neutrino detectors. This development could provide a direct measure of track length, which together with calorimetry, will provide excellent particle identification. The first technical task is therefore to examine the applicability

\footnotetext{
* Principal investigator, e-mail: fred@lanl.gov
} 
of this technology to such detectors and assess the resulting improvements in geometry, performance, and potential reductions in cost.

We plan to compute the production distributions of neutrinos from the $8-\mathrm{GeV}$ beam line at the Fermilab booster. The information will be used to guide the design of the production facility as well as the detector configuration. A second task is therefore to develop a special purpose Monte Carlo code to model production of contamination particles, particularly electron neutrinos. A full geometric software model of the detector will be built and used to study the reconstruction of neutrino events in the apparatus. A reconstruction algorithm would be developed, which coupled with the detector configuration, would be iterated to optimize the detector system. By including components such as the target, the horn, the decay volume and the beam stop in the design optimization, higher purity neutrino beams could be produced.

\section{Importance to LANL's Science and Technology Base and National R\&D Needs}

This project supports Laboratory core competencies in nuclear science, plasmas, and beams as well as complex experimentation and measurement. The neutrino oscillation experiment, which will be conducted to verify the LSND measurement, is important for Los Alamos to maintain its leadership role in these experiments. By taking the lead in the second generation experiment (assuming the effect is verified), the Laboratory will be able to claim ownership of this fundamental discovery. If our Fermilab initiative is favorably reviewed, it will lead to an approximately $\$ 10$ million experiment, which will be led by members of the Laboratory's Physics Division.

\section{Scientific Approach and Results to Date}

We have demonstrated proof of principle of a neutrino beam line design that will produce the required purity and intensity of muon-neutrinos. We have also produced an interactive Monte Carlo simulation of particle tracks in a generic detector. This is enabling us to develop the crucial intuitive understanding of the behavior of the higher-energy particles produced by the booster neutrinos. We are using this simulation to study further the feasibility of the segmented, CCD-based detector described in the proposal. The first prototypes of an extruded plastic tubing, which could form the basis for the optical isolators required for the CCD-based detector, have been obtained. 